\title{
EDITORIAL
}

\section{LA UNIVERSIDAD EN LA PROMOCIÓN Y DEFENSA DE LOS DERECHOS HUMANOS FRENTE AL COVID $19^{1}$}

\author{
Óscar Castillo Guido \\ Secretario General, Asociación de Facultades, \\ Escuelas e Institutos de Derecho de América \\ Latina. AFEIDAL. \\ Contacto: derecho@upoli.edu.ni \\ (Dhttps://orcid.org/0000-0003-2788-2771 \\ DOI https://doi.org/10.36796/biolex.v0i23.200
}

\section{Antecedente y contexto}

$\mathrm{E}$ bueno recordar el contexto de cómo surge la teorización, desarrollo y existencia jurídica-social de los derechos humanos. Cuatro hechos históricos relevantes merecen se acotados ${ }^{2}$ :

1. La Revolución Francesa y su Declaración de los Derechos del Hombre y los Ciudadanos en 1789.

2. En 1776 la declaración de independencia de los Estados Unidos y su posterior promulgación en 1791 de la Carta de Derechos Fundamentales.

3. La Revolución Industrial, que inició a mitad del siglo XVIII, culminando su auge entre 1820 y 1840 y que significó un cambio importante en nuestra vida cotidiana.

4. La Segunda Guerra Mundial que culminó en 1945, produciéndose una declaración muy importante como lo es la Declaración Universal de los Derechos Humanos, proclamada en París en 1948 y que nació como un ideal común para todos los pueblos y naciones.

\footnotetext{
${ }^{1}$ Organización Mundial de la Salud (OMS) define el COVID 19 así "La COVID-19 es la enfermedad infecciosa causada por el coronavirus que se ha descubierto más recientemente. Tanto este nuevo virus como la enfermedad que provoca eran desconocidos antes de que estallara el brote en Wuhan (China) en diciembre de 2019. Actualmente la COVID-19 es una pandemia que afecta a muchos países de todo el mundo. https://www.who.int/es/emergencies/diseases/novel-coronavirus-2019/advice-for-public/q-a-coronaviruses.

${ }^{2}$ Castillo Guido, Oscar. Manual de Derecho Constitucional. Concordancia con la Constitución Política de Nicaragua y sus reformas. - Managua: edit. PAVSA, 2012. Págs. 17-19.
} 
La Declaración establece, por primera vez, los derechos humanos fundamentales que deben protegerse en el mundo entero y ha sido traducida a más de 500 idiomas. $^{3}$

Se ha construido a partir de ello un concepto básico elemental que Naciones Unidas ha acotado así "los Derechos Humanos son derechos inherentes a todos los seres humanos, sin discriminación alguna de residencia, sexo, origen nacional o étnico, color, religión o lengua o cualquier otra condición. Todos tenemos los mismos derechos humanos, sin discriminación alguna. Estos derechos son interrelacionados, interdependientes e indivisibles."

En función de que nuestros Estados pertenecen a este concierto de naciones (ONU) y como suscriptores de las Declaraciones, Pactos y Convenios de Derechos Humanos, están obligados a promoverlos, tutelarlos y defenderlos (Derecho Internacional de Derechos Humanos) incorporándolos además en sus textos normativos, iniciando en ello en las constituciones políticas de estos y en los cuales aparecen como garantías o derechos individuales o como denominamos Derecho Fundamentales (Derecho Nacional de los Derechos Humanos).

De repente con todo esto que está pasando, a veces nos olvidamos de lo más importante, los derechos humanos, que son esos derechos fundamentales del ser humano, que ya Naciones Unidas nos refiere y quiero repetirlo en sentido más conocido como "el conjunto de los derechos con los que nace toda persona, independientemente de su raza, nacionalidad, clase social, religión, género o cualquier otro tipo de distinción posible”

Los derechos humanos están consagrados en las leyes de todas las naciones y en los tratados internacionales; son indivisibles, interdependientes, inalienables y universales. Esto significa que deben cumplirse en su totalidad (no parcialmente), que deben cumplirse todos; nadie tendrá la potestad de quitarlos, restringirlos o limitarlos en ninguna circunstancia y que aplican a todos los seres humanos sin distinción. Estos derechos hoy más que nunca debemos atesorarlos tal a como son, de orden supremo y que están por encima de cualquier tipo de ordenamiento jurídico.

Existen instituciones internacionales de alcance mundial que han velado y siguen velando por la preservación de los derechos humanos y pueden impulsar

\footnotetext{
${ }^{3}$ Organización de Naciones Unidas (ONU). Declaración Universal de Derecho Humanos. Aprobada y proclamada por la Asamblea General en su resolución 217 A(III) del 10 de diciembre de 1948. https://www.ohchr.org/EN/UDHR/Documents/UDHR_Translations/spn.pdf.
} 
sanciones para los países en donde no se les preste la debida atención. La violación de los derechos humanos es un delito de lesa humanidad que no prescribe y que debe ser mundialmente perseguido.

\section{El flagelo del COVID 19 en el 2020}

Si hace un año nos hubieran dicho que más de la mitad de la población mundial iba a estar confinada, seguro que pensaríamos que se trata de una estrategia de mercadeo de los productores de la última serie de moda o el argumento de una superproducción de Hollywood. Es más, hace tan solo unos meses fueron muchas personas las que se sorprendieron cuando conocieron las primeras medidas de confinamiento puestas en marcha por el gobierno chino a la población de Wuhan, pensando estas que era imposible llevarlas a cabo en países en los que la población tiene garantizadas sus libertades civiles. Cómo ha cambiado la película en tan solo unos meses.

Ahora bien, frente a la pandemia COVID-19 de la cual hemos sido testigos directos todas las naciones del mundo, se han puesto tan vigentes estos derechos, particularmente el derecho fundamental de la salud universal y el respeto y tutela por todos los derechos humanos.

Se ha hecho de gran valía e importancia analizar las obligaciones y las preocupaciones de los derechos humanos para evitar atentar contra la vida y la expansión del coronavirus, proteger el derecho a la salud, la libre expresión, la no discriminación y la libertad de circulación. Esto implica recordarle a los Estados los deberes a los que está jurídicamente obligado a cumplir para la prevención. Evitando así, poner en riesgo a las personas, como emana en la constitución de la Organización Mundial de la Salud, la Declaración Universal de los Derechos Humanos, Convención Americana sobre los Derechos Humanos, Pacto de san José de Costa Rica y las propias Constituciones Políticas de los Estados.

En varios países las autoridades de gobierno tomaron medidas radicales para evitar restricciones muy extensas sobre el movimiento y la libertad personal, sin embargo, esto debería suscitarse cuando esté científicamente justificado y sea necesario para no colapsar con los centros en los hospitales. Así se pueda garantizar sistemas de salud para apoyar a los infectados porque cuando se cumple con cuarentenas o este tipo de medidas el Estado, está obligado a garantizar el acceso a alimentos, servicios básicos y atención médica oportuna.

De igual manera precautelar los derechos humanos de las personas en situación de calle, con ingresos mínimos que viven al día, personas de las prisiones y centros 
de detención de inmigrantes, las personas mayores y las personas con discapacidad, entre otros. En muchos artículos y opiniones de expertos nos damos cuenta, sin embargo, que se han identificado casi que en todos los países las deficiencias en los sistemas de protección a la salud. Motivo por cual se cuestiona a los gobernantes porque todos nos encontramos vulnerables con el riesgo de la transmisión de COVID - 19, cuando se debieran ver formas más adecuadas para que todas las personas puedan acceder a la atención médica oportuna de tal forma que se garantice su bienestar.

El COVID-19 merece ser visto desde la perspectiva de los Derechos Humanos y las realidades de la población, tomando en cuenta las condiciones de vulnerabilidad que en el presente existen, tanto a las personas que se expusieron $\mathrm{y}$ hoy se encuentran en los hospitales siendo intervenidos.

Aclarando el concepto de vulnerabilidad que es bien sonado por diversas situaciones, todos y cada uno de nosotros son y están en una u otra característica de ésta, siendo que le son propias al ser humano, como la consciencia, la capacidad de amar, la empatía y la voluntad de supervivencia. No existe quien pueda considerarse inmortal. No hay quien sea invulnerable. Lo mismo sucede con el COVID-19 nadie puede hacerse ajeno y actuar irresponsablemente arriesgando la vida de su familia y entorno en general.

Lo cierto es que el Derecho Internacional contempla la restricción de determinados derechos y libertades. $\mathrm{Y}$ esto es aplicable cuando existen serias amenazas a la salud pública o en un contexto de emergencia donde está en peligro la vida de la población, como es el caso de una pandemia global. Esto está recogido en los Principios de Siracusa y fueron aprobados en agosto de 1984 en esta ciudad italiana4. Sí, está permitido, pero con condiciones. Estas se pueden resumir en tres palabras: deben ser legales, necesarias y proporcionadas.

Tres derechos humanos se han visto afectados directamente por la COVID-19, los derechos de libre circulación, con prohibiciones que van desde viajar al extranjero o incluso salir de nuestras casas (confinamiento); el de libertad de reunión no pudiendo realizar actividades de forma presencial aunque esto se supera con ahora reuniéndonos en forma virtual o bien por las actuales desescaladas (al menos por ahora) que se ha reducido esto con las medidas de extrema precauciones $y$, el derecho a la privacidad, donde en un país donde la familia esta

\footnotetext{
${ }^{4}$ Principios de Siracusa sobre las disposiciones de limitación y derogación del Pacto Internacional de Derechos Civiles y Políticos. Naciones Unidas/Consejo Económico y Social. Comisión De Derechos Humanos $41^{\circ}$ Período De Sesiones. https://www.civilisac.org/civilis/wp-content/uploads/principios-de-siracusa-1.pdf
} 
confinada es difícil delimitar la esfera pública de la familiar, el teletrabajo convirtiendo el hogar en oficina de trabajo y también lo que se ha visto con la afectada protección de datos personales, en donde incluso son las aplicaciones que en algunos países permiten recoger datos de geolocalización y que se están utilizando para estudiar la movilidad de la población.

Situaciones excepcionales, requieren medidas excepcionales. Sin embargo, la pandemia no debe suponer un retroceso en las libertades civiles que tanto nos ha costado conquistar, y por ende la Universidad no debe ser una entidad que calle ante esto, y no solo eso, que deje de hacer lo propio desde su propia naturaleza de formación de profesionales con valores y principios que tiendan a humanizarse frente a estos contextos.

\section{Las universidades en la promoción y defensa de los derechos humanos. Una agenda permanente}

En el mismo sentido, no debemos olvidar lo que somos dentro del sistema educativo en la que, casi en todos nuestros países incorporamos un fin común: "la educación superior y el conocimiento como un bien público y social, que debe propiciar el ejercicio de las libertades fundamentales, reconociendo la plena vigencia de los derechos humanos, sin discriminación alguna.”

Si bien la tematización de los derechos humanos ha estado presente a lo largo de la historia de nuestras Universidades, interesa puntualizar que esta dimensión es colocada de modo explícito, transversalizando todas sus funciones, a partir de las luchas reivindicativas y del amplio debate que nos dimos allá en 1918, con la reforma de Córdoba y en la que alcanzamos la autonomía universitaria sustentada en los valores de libertad y justicia.

Mediante esa construcción filosófica reafirmamos el compromiso con los valores democráticos y republicanos, en defensa de la soberanía, la independencia, justicia y libertad y con la búsqueda de respuestas a problemas sociales que afectan principalmente a los sectores en condición de vulnerabilidad cuyos derechos esenciales no están garantizados.

Entonces, bajo esos principios y valores, las Universidades en tiempos de pandemia estamos obligados:

1. A poner en práctica la promoción y defensa de los Derechos Humanos, exigiendo y velando que nuestros Estados no tomen 
medidas de "emergencia" que vulneren o sean en perjuicio de reducir los servicios de salud, educación, empleo y bienestar.

2. Debemos impulsar desde nuestras instituciones los consensos necesarios para que todos los actores sociales y no solo el Estado desarrollen planes y programas incluyentes y participativos con un enfoque de Derechos Humanos. Nuestro foro institucional debe ser neutral y abierto ante esto, permanente y aportativo a esos consensos. Tenemos las plataformas virtuales, los docentes, investigadores y programas de extensión para hacerlo.

3. $\mathrm{Al}$ ser nosotros centros de pensamiento y de formación, nos obliga aparecer fomentando y promoviendo la cultura de los derechos humanos, no solo haciendo transversal su estudio a través de nuestros programas o planes de estudios, sino haciendo investigación y difundiéndola en nuestros medios físicos y virtuales.

4. Debemos hacer que nuestros programas de investigación y extensión se pongan al servicio de este flagelo a fin de contribuir a reducir el impacto de este. Debemos procurar que surjan propuestas, producto del análisis y debate científico, de orden social, económico y jurídico para enfrentar en esos órdenes la pandemia del COVID 19.

En tiempos de COVID 19, las facultades de derecho debemos colocarnos en primera fila al servicio de la sociedad, realizando debates nacionales propositivos a través de congresos, jornadas académicas, foros científicos jurídicos, de publicaciones en nuestras revistas que coadyuven y propicien la promoción, defensa y tutela de los derechos humanos.

5. Debemos ser las voces críticas y propositiva ante las políticas o medidas que a fin de atender la crisis sanitaria, pongan en riesgo los derechos humanos de las personas. Nuestro silencio puede volverse cómplice, en muchas realidades.

6. Debemos ser capaces de identificar los desafíos que la sociedad en la actualidad vive en relación con el campo de los Derechos Humanos exigiendo al Estado el cumplimiento de su responsabilidad en la prevención, sanción y erradicación de toda forma de violación a los 
mismos, así como la promoción y protección de los derechos económicos, sociales, culturales y ambientales.

7. Promover el debate público sobre las violaciones a los derechos humanos, en el pasado reciente y en la actualidad, asumiendo colectivamente la lucha simbólica entre definiciones retóricas e interpretaciones legítimas.

8. Propiciar un trabajo formativo que promueva el respeto a la multiculturalidad, a la identidad de género, a las libertades fundamentales y a la democracia, a partir de su visibilizarían como contenidos curriculares, de investigación y de extensión, de todas las propuestas educativas. En tiempos de pandemia debemos observar las directrices que sobre el COVID 19 emitiera la Oficina del Alto Comisionado de Naciones Unidas para los Derechos Humanos (OACNUDH). ${ }^{5}$

Cuantos temas, no creen ustedes, solo de esas directrices pudiéramos realizar tesis de posgrados, monografías, congresos, investigaciones, foros, escribir artículos científicos, etc. Son temas muy sensibles ya actuales frente al coronavirus.

9. Coordinar un trabajo interinstitucional con Áreas de derechos humanos de universidades nacionales y extranjeras, aprovechando las redes, asociaciones o uniones que se tienen. La alianza interinstitucional entre la UPOLI y la UNISON para la edición de esta revista es un vivo ejemplo de estas coordinaciones. De igual manera hacerlo con las organizaciones sociales, gremiales, con los organismos de derechos humanos y con los poderes del Estado.

Se pudiera seguir enunciando más acciones, pues el tema de derechos humanos es tan incansable e inagotable. Cuando se trata del ser humano y sus derechos nunca se puede concluir fácilmente. Es fascinante y nos envuelve a todos los académicos y es por ello por lo que, desde las aulas, desde la red, desde la virtualidad, desde el auditorio o el foro, desde esta revista conjunta, debemos

\footnotetext{
${ }^{5} \mathrm{Al}$ respecto el llamado de la OACNUD señala como desafío principal "El COVID-19 pone a prueba a sociedades, gobiernos, comunidades y particulares. Esta es una época de solidaridad y colaboración para hacer frente al virus y atenuar los efectos, a menudo no deseados, de las medidas aplicadas para detener su propagación. El respeto de los derechos humanos en todo su espectro, que abarca tanto a económicos, sociales y culturales como civiles y políticos, será fundamental para el éxito de la respuesta de la sanidad pública y la recuperación de la pandemia”. Directrices relativas a la COVID 19. https://www.ohchr.org/SP/NewsEvents/Pages/COVID19Guidance.aspx
} 
convertimos en ese virus contagioso que enferme a nuestros estudiantes para que estos con tanta nobleza asuman y recojan la bandera de esta noble tarea de defender los derechos humanos de las personas. Siendo así habremos cumplido con nuestra misión formadora.

\section{Referencias bibliográficas}

Castillo, Óscar, Manual de Derecho Constitucional. Concordancias con la Constitución Política de Nicaragua y sus reformas. Managua: PAVSA, 2012.

Oficina del Alto Comisionado de las Naciones Unidas para los Derechos Humanos. Directrices relativas a la COVID-19, 2020. https://www.ohchr.org/ Documents/Events/COVID-19_Guidance_SP.pdf.

Organización de las Naciones Unidas:

Declaración Universal de Derechos Humanos, 1948.

Derechos humanos, Naciones Unidas, 2017. https://www.un.org/es/sections/ issues-depth/human-rights/index.html.

Organización de las Naciones Unidas y Consejo Económico y Social. Principios de Siracusa sobre las disposiciones de limitación y derogación del Pacto Internacional de Derechos Civiles y Políticos, 1984.

Organización Mundial de la Salud. Preguntas y respuestas sobre la enfermedad por coronavirus (COVID-19), world health organization, 2020. https://www.who.int /es/emergencies/diseases/novel-coronavirus-2019/advice-for-public/q-a-corona viruses. 